Research Article

\title{
The Consumption of Cannabis by Fibromyalgia Patients in Israel
}

\author{
George Habib ${ }^{1}{ }^{1}$ and Irit Avisar ${ }^{2}$ \\ ${ }^{1}$ Rheumatology Unit, Laniado Hospital and Rheumatology Clinic, Nazareth Hospital and Faculty of Medicine, \\ Technion-Israel Institute of Technology, Haifa, Israel \\ ${ }^{2}$ Cann Pharmaceutical, Israel
}

Correspondence should be addressed to George Habib; gshabib@gmail.com

Received 6 June 2018; Accepted 15 July 2018; Published 22 July 2018

Academic Editor: Giustino Varrassi

Copyright (C) 2018 George Habib and Irit Avisar. This is an open access article distributed under the Creative Commons Attribution License, which permits unrestricted use, distribution, and reproduction in any medium, provided the original work is properly cited.

Objective. To report on the habits of cannabis consumption among fibromyalgia patients in Israel. Patients and Methods. An Internet-based questionnaire was posted to three large fibromyalgia Facebook groups in our country. The questionnaire was anonymous and included demographic, clinical, and cannabis-related questions, including acquisition of a license for medical cannabis (MC) method and amount of cannabis consumption; need to buy cannabis beyond the medical allowance; effect of cannabis on pain, sleep, depression, and anxiety; adverse effects of cannabis; feelings of dependence on cannabis or other meds; the involvement of family members; tendency to drive after using cannabis; and employment and social disability status. Results. Of 2,705 people, $383(14 \%)$ responded to the questionnaire, with a mean age of $42.2 \pm 14.2$ years. Of the responders, $84 \%$ reported consuming cannabis, and $44 \%$ were licensed for MC. The mean amount per month of cannabis consumed was $31.4 \pm 16.3 \mathrm{~g}$, and $80 \%$ of cannabis consumers (CC) smoked pure cannabis or cannabis mixed with tobacco. Pain relief was reported by $94 \%$ of CC, while $93 \%$ reported improved sleep quality, $87 \%$ reported improvement in depression, and $62 \%$ reported improvement in anxiety. Of MC-licensed CC, 55\% bought cannabis beyond the medical allowance on the black market. Adverse effects were reported by $12 \%$ of CC. Only $8 \%$ reported dependence on cannabis. Most CC (64\%) worked either full- or part-time jobs, and 74\% reported driving "as usual" under cannabis use. Conclusions. Cannabis consumption among fibromyalgia patients in our country is very common and is mostly not licensed. Nearly all CC reported favorable effects on pain and sleep, and few reported adverse effects or feeling of dependence on cannabis.

\section{Introduction}

Fibromyalgia is a chronic pain syndrome characterized primarily by diffuse musculoskeletal pain, fatigue, and mood and sleep disturbances [1]. It affects women more frequently than men and has a genetic preponderance [2]. It is not uncommon, as its prevalence in the general population is estimated around 7\% [3].

Fibromyalgia might have a tremendous physical and psychological impact on patients and may lead to disability [4]. Currently, there is no cure for this syndrome in most patients, and the main treatment is usually pain control medication. These medications include pregabalin and duloxetine [5]. Some patients may benefit from benzodiazepines, tricyclic antidepressants, and other antidepressants [6]. Many of these medications are associated with adverse effects that affect compliance.

Cannabis is considered an illicit drug in most countries, including our country. However, it is widely used in both illegal and legal fashions [7]. In legal forms, it is used primarily by cancer patients. Many of its users report the high potential of cannabis to suppress pain and induce sleep and calmness [8]. Due to these favorable properties, cannabis has been legislated during the last few years, in some states in the United States and other countries for medical use $[9,10]$. In our country, medical cannabis (MC) is licensed by the Medical Cannabis Agency (MCA), a special committee at the Ministry of Health, for specific indications, including uncontrolled pain in cancer patients, uncontrolled gastrointestinal symptoms in Crohn's patients, uncontrolled seizures, uncontrolled 
TABLE 1: Demographics of all participants with fibromyalgia who responded to the questionnaire (383 participants).

\begin{tabular}{lc}
\hline Parameter & Results (\%) \\
\hline (i) Number of females & $325(85)$ \\
(ii) Age (yrs) & $42.2 \pm 14.2,19-74 *$ \\
(iii) Duration of fibromyalgia (yrs) & $8.26 \pm 7.8,1-40 *$ \\
(iv) Social status & $238(62)$ \\
$\quad$ Married & $57(15)$ \\
$\quad$ Divorced & $85(22)$ \\
$\quad$ Single & $4(1)$ \\
$\quad$ Widow & $1.81 \pm 1.42,0-4 *$ \\
(v) Number of kids & \\
\hline
\end{tabular}

* mean $\pm \mathrm{SD}$, range.

Parkinson's disease, posttraumatic stress disorder (PTSD), unresponsive diabetic neuropathy, and other indications such as degenerative or inflammatory musculoskeletal problems. The application for MC licensing is sent directly to the MCA by the subspecialty physician. Fibromyalgia is not considered as one of these indications, based on the recommendation of the Rheumatology Association of our country. However, fibromyalgia patients who are followed also at other subspecialties such as pain clinic and/or gastroenterology (GI) clinic for GI symptoms and/or followed by psychiatric for mood disturbance might get approval for MC. While many are not approved for MC, many patients with fibromyalgia in our country have experience using medical or nonmedical cannabis.

There are no studies about the prevalence of cannabis consumption by fibromyalgia patients in our country. There are very few studies in the literature about the use of cannabis by fibromyalgia patients from other parts of the world [11, 12]. In this study, we report on the habits of cannabis consumption of three large fibromyalgia social media groups in our country.

\section{Materials and Method}

Members of three large Facebook groups in our country with fibromyalgia diagnosed by a rheumatologist were asked to fill out an anonymous questionnaire online. The questionnaire included demographic, clinical, and cannabis-related parameters, including age; social status; duration of fibromyalgia; current treatment; amount and method of cannabis consumption (smoking, vaporization, oil); acquisition of a license for MC; prior application for MC; sufficiency of the legal allowing of MC; effect of cannabis on pain, sleep, anxiety, and depression; feelings of addiction to cannabis; feelings of addiction to other meds; tendency to drive a motor vehicle under cannabis treatment; employment status; and impact of cannabis on employment and social security disability.

This study was approved by the local ethics committee of our hospital, and all participants agreed (anonymously) through the net to fill out the questionnaire as a part of research.

2.1. Statistical Analysis. For statistical analysis, simple frequency measures were used using Excel Microsoft software.

\section{Results}

Out of the fibromyalgia social media groups' 2,705 members, 383 participants $(\sim 14 \%)$ with fibromyalgia diagnosed by a rheumatologist responded to the questionnaire.

Table 1 summarizes the demographics of the patients. Of these, $85 \%$ were female with a mean duration of fibromyalgia of $8.26 \pm 7.8$ years.

Table 2 summarizes the data regarding cannabis consumption and related issues. Approximately $84 \%$ of the participants reported consuming cannabis with a mean dose of $31.4 \pm 16.3 \mathrm{~g}$ per month. Only around $12 \%$ of cannabis consumers (CC) reported adverse effects, and approximately 92\% denied feeling addicted to cannabis.

Table 3 summarizes the medical and nonmedical impact of cannabis. Participants reported pain improvement and better quality of sleep under cannabis consumption at $94 \%$ and 93\%, respectively. Part- or full-time jobs were held by $64 \%$ of the patients under cannabis consumption. Around $72 \%$ of the patients continued to drive while under cannabis treatment. Most of the patients did not file a request for social security disability; of those who did apply for social disability, the mean disability was $\sim 51 \%$.

\section{Discussion}

There were many interesting findings in our study. The main finding was that nearly $84 \%$ of those who responded to the questionnaire were CC. This rate is very high, and it raises the question of whether the responders of the questionnaire represent the whole community of the three fibromyalgia Facebook groups. A response rate of $14 \%$ to an Internet questionnaire is considered an accepted rate [13, 14], and the correlation between a paper-based survey and electronic survey was high in one study [13]. This may actually indicate that more than $80 \%$ of the total number $(2,705)$ of patients in the fibromyalgia social media groups were consuming cannabis.

The rate of approval for MC licensing by the MCA was also relatively high $(142 / 317,45 \%)$ among the fibromyalgia participants in our study. However, it must be remembered that many of these patients likely had concurrent medical conditions that facilitated or were the main reason for approval. Unfortunately, the questionnaire did not include 
TABLE 2: Cannabis and other treatment related parameters of all participants.

\begin{tabular}{|c|c|}
\hline Parameter & Results (\%) \\
\hline (i) Total number of patients who uses cannabis & $323 / 383(84)$ \\
\hline (ii) No. of patients licensed for MC & $142 / 323(44)$ \\
\hline (iii) No. of patients who consume cannabis without a license & $181 / 323(56)$ \\
\hline (iv) No. of patients who applied for MC license & $317 / 383(83)$ \\
\hline (v) No. of patients who appealed after refusal & 65 \\
\hline \multicolumn{2}{|l|}{ (vi) No. of appeals prior to licensing } \\
\hline 1 & 27 \\
\hline 2 & 16 \\
\hline 3 & 10 \\
\hline (vii) No. of licensed patients reporting MC supplied not enough & $94 / 142(66)$ \\
\hline (viii) No. of licensed patients who buy in black market & $78 / 142(55)$ \\
\hline (ix) Amount of cannabis consumed/ month (g) by all the patients & $31.4 \pm 16.3,5-150 *$ \\
\hline (x) Amount of money paid for cannabis in the black market (US\$) & $106 \pm 206,29-1428 *$ \\
\hline (xi) Frequency of cannabis consumption/day & $4.7 \pm 3.96,1-20$ \\
\hline (xii) No. of patients using $\geq 3$ species of $\mathrm{MC}$ & $63 / 142(\sim 44)$ \\
\hline (xiii) No. of patients using 2 species of MC & $50 / 142(\sim 35)$ \\
\hline (xiv) No. of patients using 1 species of MC & $29 / 142(\sim 21)$ \\
\hline \multicolumn{2}{|l|}{ (xv) Method of cannabis consumption by all participants } \\
\hline Smoking with cigarette & $241 / 323(63)$ \\
\hline Smoking pure cannabis & $85(\sim 17)$ \\
\hline Oil under tongue & $18(\sim 5)$ \\
\hline Vaporizing & $57(\sim 15)$ \\
\hline (xvi) No. of patients reporting adverse effects from cannabis & $36 / 308(12)$ \\
\hline (xvii) No. of patients reporting feeling dependent on cannabis & $25 / 304(8)$ \\
\hline (xviii) No. of patients reporting adverse effects from regular meds for fibromyalgia prior to cannabis use & $336 / 357(94)$ \\
\hline (xix) No. of patients reporting dependence on regular meds & $229 / 348(66)$ \\
\hline \multicolumn{2}{|l|}{ (xx) Patients' report on the use of other meds under cannabis } \\
\hline Using the same other meds & $45 / 304(15)$ \\
\hline Sopped all other meds & $134 / 304(44)$ \\
\hline Consuming less other meds & $125 / 304(41)$ \\
\hline
\end{tabular}

* mean $\pm \mathrm{SD}$, range.

No. $=$ Number.

questions regarding specific diseases or conditions such as malignancy that the patients might also have, in the interest of improving compliance with the questionnaire. Licenses for MC use were issued by the MCA after an appeal in about $37 \%$ of the MC-licensed patients; among some, three appeals were required prior to approval. Therefore, appealing for MC licensing after refusal by the MCA is always recommended.

The mean quantity of cannabis consumed by all CC was nearly $1 \mathrm{~g}$ per day, and nearly two-thirds of the patients licensed for MC reported that their supplied quantity was not sufficient. More than half $(\sim 55 \%)$ reported buying cannabis from the black market.

It must be remembered that the price of the supplied MC for licensed patients is fixed regardless of the quantity supplied, standing at about \$120 a month, while those buying on the black market sometimes pay as high as $\$ 1,450$ a month to get cannabis, figures that are quite high. These figures reflect the high demand for cannabis by fibromyalgia patients in our country.
Most of MC consumers used three or more species of cannabis. This indicates that one species of cannabis cannot suffice for the different complaints of the patients, such as pain, insomnia, anxiety, or lack of energy. Different species and different concentrations of tetrahydrocannabinol (THC) and cannabidiol (CBD) were needed to tackle these complaints. Unfortunately, we did not specifically document the concentration of THC or CBD in each species.

Most of the patients used unlicensed cannabis by smoking it mixed with tobacco, while those using MC smoked it without mixing it. Some used vaporization and some used oral oil drops. Vaporization appealed primarily to women who did not want to smoke, while cannabis oil drops were considered weak in terms of efficacy. Oil drops, however, had a long term effect and were usually used as a complement to smoking or vaporization. The other advantage of oil drop preparations of cannabis is the accurate measurement of both THC and CBD that patients eventually get.

As expected, a high percentage of patients (94\%) reported pain relief; the impact on sleep, a major problem among 
TABLE 3: Impact of cannabis on medical and nonmedical parameters.

\begin{tabular}{lc}
\hline Parameter & Results (\%) \\
\hline (i) No. of patients reporting pain relief due to cannabis & $303 / 323(94)$ \\
(ii) No. of patients reporting better quality of sleep & $281 / 302(93)$ \\
(iii) No. of patients reporting improvement of depression & $172 / 202(85)$ \\
(iv) No. of patients reporting improvement of anxiety & $122 / 235(62)$ \\
(v) No. of patients reporting improving of daily activity & $237 / 291(81)$ \\
(vi) Patients reporting sports activity prior to cannabis & $89 / 309(32)$ \\
(vii) Patients reporting sport activity under cannabis & $129 / 301(43)$ \\
(viii) Patients report on work & $152 / 323(47)$ \\
Working full-time job under cannabis & $55 / 323(17)$ \\
Partial time & $116 / 323(36)$ \\
Not working at all & $233 / 323(72)$ \\
(ix) No. of patients driving under cannabis & $29 / 323(9)$ \\
As usual & $61 / 323(19)$ \\
Not at all & $146 / 374(39)$ \\
I don't drive at all & $51.3 \pm 29.7,0-100 *$ \\
(x) No. of patients with social security disability & $214 / 323(66)$ \\
(xi) Percent of disability & $74 / 323(23)$ \\
(xii) No. of patients who informed family members about cannabis use & \\
Yes &
\end{tabular}

$*$ mean $\pm \mathrm{SD}$, range.

No. $=$ number.

fibromyalgia patients, was similar, making cannabis a versatile remedy. It also improved depression and anxiety, though in a lower percentage of patients. All these effects make cannabis very appealing to fibromyalgia patients.

Only $12 \%$ of all cannabis users in our study reported adverse effects, compared to $94 \%$ reporting adverse effects from other pain meds prior to cannabis use. Most cannabisrelated adverse effects were mild and transient such as eye or throat irritation (data not shown). In addition, only $8 \%$ of cannabis users felt dependent on cannabis, as opposed to $66 \%$ feeling dependent on other pain meds. On the other hand, nearly $85 \%$ of the patients either completely stopped taking any other pain medications or reduced the dosage of other meds. This reflects the advantage of cannabis over other meds in alleviating pain in addition to its favorable effects on sleep and mood.

Eighty-one percent $(81 \%)$ of the patients reported an improvement in their capacity to perform daily activities, and $64 \%$ reported going back to part- or even full-time jobs. These figures are very important to the patients personally, to their families, and to society in general. We could not find data in the literature about this issue among patients treated with cannabis for different indications. However, in a large study assessing the impact of cannabis as an illicit drug, a detrimental effect was found on employment and labor force [15].

Although the MCA explicitly explains that it is forbidden to drive under cannabis use, most patients do drive under the effect of cannabis, with only about $21 \%$ of licensed patients not driving at all under cannabis treatment. It could be that those patients who drive under the influence of cannabis feel focused enough to proceed with driving.

Although fibromyalgia is not listed among the medical conditions for social security liability, there is an increasing awareness by social security employees, and more and more patients are approved for disability benefits, although the percent of disability granted for these patients is still lower than the real physical and functional disabilities they face. Still, many patients are granted no social security disability, and the $51 \%$ figure in our study actually reflects total disability, mainly due to these patients' other diseases and medical conditions.

Eighty-nine percent (89\%) of the patients do not keep their use of cannabis a secret but share this information with their close family members. This fact probably reflects the favorable social effect of cannabis enabling patients to spend more time with their family members rather than seeking isolation and the increased general awareness of this type of treatment in the country.

The results of our study should encourage both the Rheumatology Association in our country and the MCA to reconsider their stand on cannabis and include fibromyalgia among the indications for MC under certain restrictions.

\section{Data Availability}

All data used in this study is shown in the Results.

\section{Conflicts of Interest}

The authors declare that they have no conflicts of interest. 


\section{References}

[1] M. Gostine, F. Davis, B. A. Roberts et al., "Clinical Characteristics of Fibromyalgia in a Chronic Pain Population," Pain Practice, vol. 18, no. 1, pp. 67-78, 2018.

[2] L. M. Arnold, J. Fan, I. J. Russell et al., "The fibromyalgia family study: A genome-wide linkage scan study," Arthritis \& Rheumatology, vol. 65, no. 4, pp. 1122-1128, 2013.

[3] A. Vincent, B. D. Lahr, F. Wolfe et al., "Prevalence of fibromyalgia: A population-based study in Olmsted County, Minnesota, utilizing the Rochester epidemiology project," Arthritis Care \& Research, vol. 65, no. 5, pp. 786-792, 2013.

[4] V. Segura-Jiménez, I. C. Álvarez-Gallardo, A. Carbonell-Baeza et al., "Fibromyalgia has a larger impact on physical health than on psychological health, yet both are markedly affected: the alÁndalus project," Seminars in Arthritis and Rheumatism, vol. 44, no. 5, pp. 563-570, 2015.

[5] S. Kia and E. Choy, "Update on Treatment Guideline in Fibromyalgia Syndrome with Focus on Pharmacology," Biomedicines, vol. 5, no. 2, Article ID 20, 2017.

[6] PG. O'Malley, E. Balden, G. Tomkins, J. Santoro, K. Kroenke, and JL. Jackson, "Treatment of fibromyalgia with antideppressants," Journal of General Internal Medicine, vol. 15, pp. 659-666, 2000.

[7] United Nations Office on Drugs and Crime (UNODC), Nations Office on Drugs and Crime, United Nations Office on Drugs and Crime, Vienna, Austria, 2015.

[8] A. Reiman, M. Welty, and P. Solomon, "Cannabis as a Substitute for Opioid-Based Pain Medication: Patient Self-Report," Cannabis and Cannabinoid Research, vol. 2, no. 1, pp. 160-166, 2017.

[9] W. D. Troutt and M. D. DiDonato, "Medical Cannabis in Arizona: Patient Characteristics, Perceptions, and Impressions of Medical Cannabis Legalization," Journal of Psychoactive Drugs, vol. 47, no. 4, pp. 259-266, 2015.

[10] G. D. Ko, S. L. Bober, S. Mindra, and J. M. Moreau, "Medica cannabis- the Canadian perspective," The Canadian Perspective, vol. 9, pp. 735-744, 2016.

[11] J. Fiz, M. Durán, D. Capellà, J. Carbonell, M. Farré, and A. V. García, "Cannabis Use in Patients with Fibromyalgia: Effect on Symptoms Relief and Health-Related Quality of Life," PLoS ONE, vol. 6, no. 4, Article ID e18440, 2011.

[12] B. J. Piper, M. L. Beals, A. T. Abess et al., "Chronic pain patients' perspectives of medical cannabis," Pain, vol. 158, no. 7, pp. 13731379, 2017.

[13] M. W. Steffen, M. H. Murad, J. T. Hays et al., "SelfReport of Tobacco Use Status: Comparison of Paper-Based Questionnaire, Online Questionnaire, and Direct Face-toFace Interview-Implications for Meaningful Use," Population Health Management, vol. 17, no. 3, pp. 185-189, 2014.

[14] S. M. Kongsved, M. Basnov, K. Holm-Christensen, and N. H. Hjollund, "Response rate and completeness of questionnaires: A randomized study of internet versus paper-and-pencil versions," Journal of Medical Internet Research, vol. 9, no. 3, Article ID e25, 2007.

[15] I. Popovici and M. T. French, "Cannabis Use, Employment, and Income: Fixed-Effects Analysis of Panel Data," The Journal of Behavioral Health Services \& Research, vol. 41, no. 2, pp. 185202, 2014. 


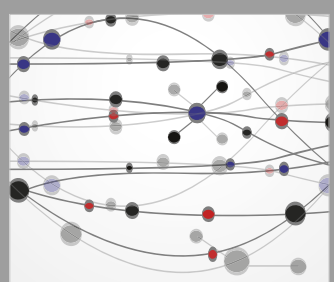

The Scientific World Journal
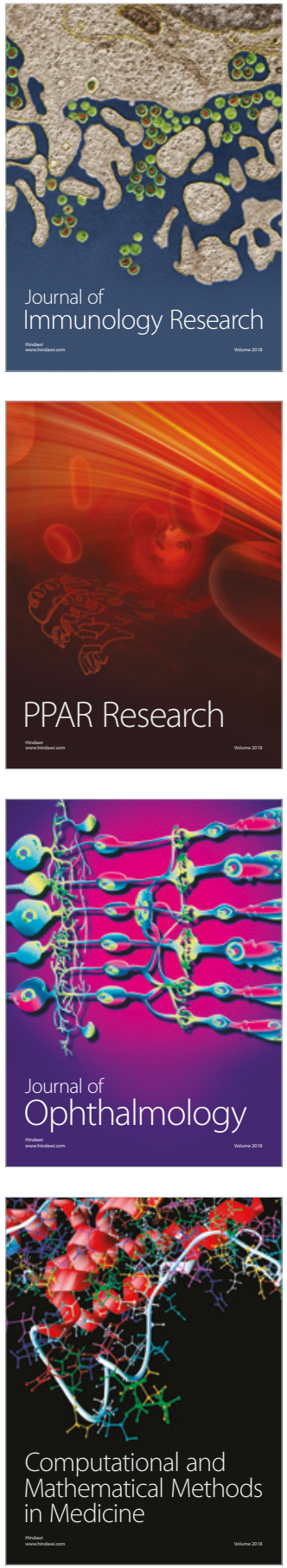

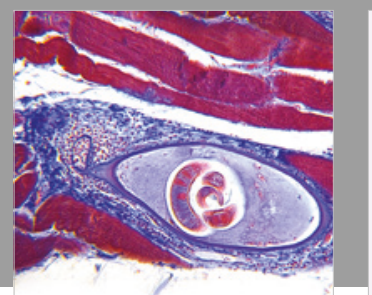

Gastroenterology Research and Practice

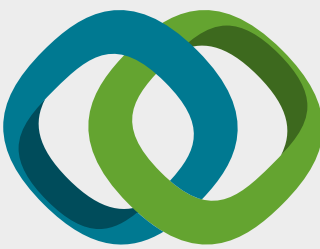

\section{Hindawi}

Submit your manuscripts at

www.hindawi.com
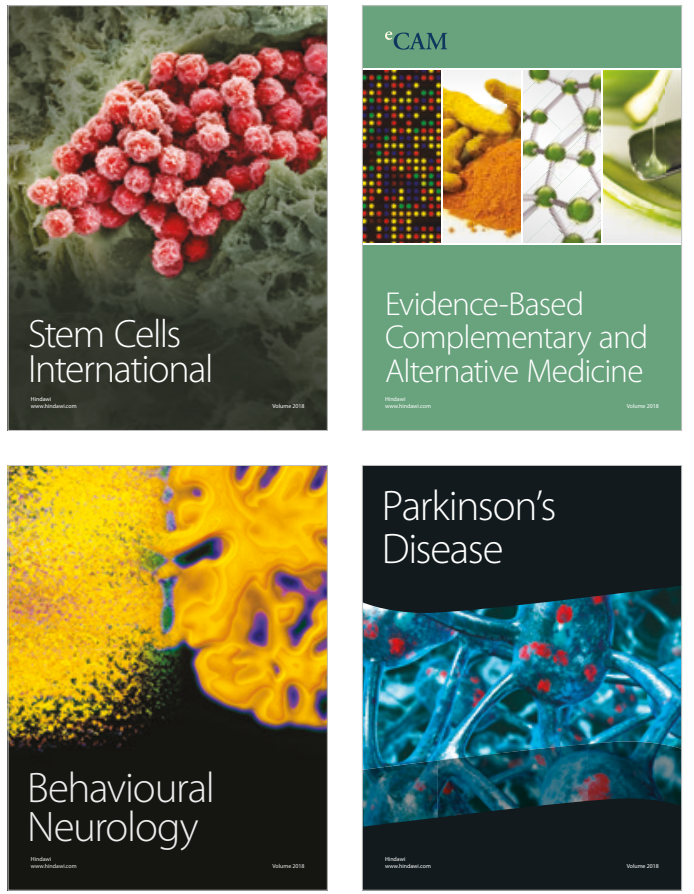

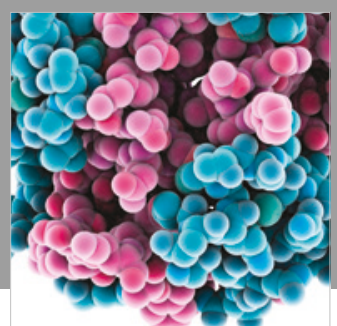

ournal of

Diabetes Research

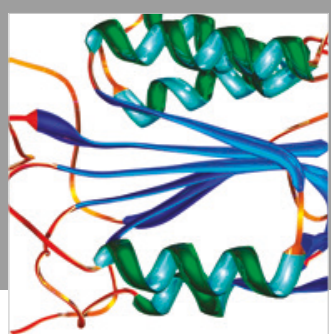

Disease Markers
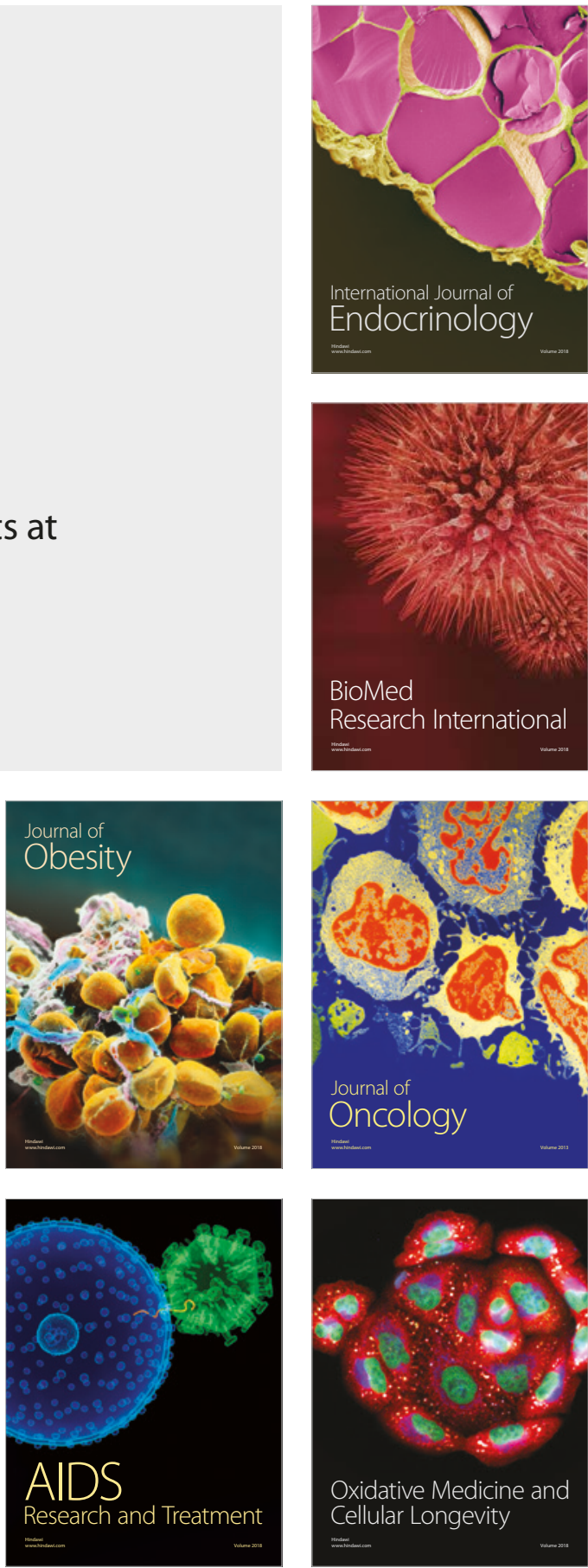